\title{
The uptake of different iron salts by the yeast Saccharomyces cerevisiae
}

\author{
Fernanda Gaensly ${ }^{1}$, Geraldo Picheth ${ }^{1,2}$, Debora Brand ${ }^{1,3}$, Tania M.B. Bonfim ${ }^{1,3}$ \\ ${ }^{1}$ Programa de Pós Graduação em Ciências Farmacêuticas, \\ Universidade Federal do Paraná, Curitiba, PR, Brazil. \\ ${ }^{2}$ Departamento de Departamento de Análises Clínicas, Universidade Federal do Paraná, Curitiba, PR, \\ Brazil. \\ ${ }^{3}$ Departamento de Farmácia, Universidade Federal do Paraná, Curitiba, PR, Brazil.
}

Submitted: September 19, 2012; Approved: September 9, 2013.

\begin{abstract}
Yeasts can be enriched with microelements, including iron; however, special physicochemical conditions are required to formulate a culture media that promotes both yeast growth and iron uptake. Different iron sources do not affect biomass formation; however, considering efficacy, cost, stability, and compatibility with Saccharomyces cerevisiae metabolism, ferrous sulphate is recommended.
\end{abstract}

Key words: yeast, Saccharomyces cerevisiae, iron uptake, iron sources, biomass formation.

Saccharomyces cerevisiae yeast strains represent a valuable food supplement providing proteins and vitamins to human diet (Chang et al., 2005; Mrvcic et al., 2007). This yeast is also employed in studies regarding the interaction between microelements and microorganisms because it is easy to cultivate and a high cellular biomass yield can be obtained in a short period of time. In certain physicochemical conditions, yeasts are able to bound to different minerals and incorporate them at concentrations higher than its physiological concentrations (Stehlik-Thomas et al., 2003; Mrvcic et al., 2007).

Yeast metal enrichment can be obtained by adding an inorganic salt of the desired metal in the cultivation media (Donmez et al., 1999; De Siloniz et al., 2002; Gligic et al., 2004; De Nicola et al., 2009). Metal uptake by yeast cells is a complex process and depends on the metal ion chemistry, the specific properties of the organism, the cell physiology, the physicochemical influences of the environment, and the experimental factors, such as the $\mathrm{pH}$, the temperature, the aeration, and the presence of other ions in solution. The growth conditions influence considerably yeast cells composition and their binding ability to metals present in the culture media (Gligic, et al., 2003; Dostalek et al., 2004; Pas et al., 2007).

The metals are incorporated into the yeast cells in a variety of ways, including the production of metal-binding proteins, mineralization, or sequestration in vacuoles (Ra- guzzi et al., 1988; Gaudreau et al., 2001; Gharieb et al., 2004; Shoeib et al., 2007).

Iron is an essential nutrient to yeasts, although toxic depending on its concentration in the growth media. For this reason, the iron uptake and utilization by yeasts are tightly controlled (Askwith et al., 1996). The yeast Saccharomyces cerevisiae can easily thrive in environments when iron is too scarce or too abundant, so it is suggested that it responds to iron depletion by altering its utilization, preserving this nutrient in essential metabolic pathways (Philpott et al., 2008).

Determining the optimal concentration of a microelement in the culture media as well as the concentration in which it will inhibit yeast biomass formation is a complex process that depends on the microorganism employed and on the composition of the culture media. The culture media complexity, metallic ions interactions with organic compounds and with other metallic ions, $\mathrm{pH}$, and the use of mutual microelements transport systems by the microorganisms can difficult the precise determination of these concentrations (Mrvcic et al., 2007).

In the present work, the yeast Saccharomyces cerevisiae was isolated from fresh compressed baker's yeast ferment and cultivated in yeast media $(10 \mathrm{~g} / \mathrm{L}$ dextrose; $5 \mathrm{~g} / \mathrm{L}$ peptone; $3 \mathrm{~g} / \mathrm{L}$ yeast extract and $3 \mathrm{~g} / \mathrm{L}$ malt extract) containing 15 and $25 \mathrm{mg} \mathrm{Fe} / \mathrm{L}$ of ferrous sulphate $\left(\mathrm{FeSO}_{4} .7 \mathrm{H}_{2} \mathrm{O}\right)$, ferric sulphate $\left(\mathrm{Fe}_{2}\left(\mathrm{SO}_{4}\right)_{3} .5 \mathrm{H}_{2} \mathrm{O}\right)$, ferrous 
chloride $\left(\mathrm{FeCl}_{2}\right)$, ferric chloride $\left(\mathrm{Cl}_{3} \mathrm{Fe} \cdot 6 \mathrm{H}_{2} \mathrm{O}\right)$, ferric nitrate $\left(\mathrm{Fe}\left(\mathrm{NO}_{3}\right)_{3} .9 \mathrm{H}_{2} \mathrm{O}\right)$, ferric citrate $\left(\mathrm{C}_{6} \mathrm{H}_{5} \mathrm{FeO}_{7}\right)$, or ferric EDTA $\left(\mathrm{C}_{10} \mathrm{H}_{12} \mathrm{FeN}_{2} \mathrm{NaO}_{8}\right)$ (all iron salts supplied by Sigma, Brazil), and determinations of the iron uptake and the biomass formation were performed. The iron concentrations to supplement growth media (15 and $25 \mathrm{mg} \mathrm{Fe} / \mathrm{L}$ ) represent respectively 50 and 80 times the yeasts' physiological requirement for iron.

Cells harvested from yeast cultures grown in yeast media agar slants $\left(28^{\circ} \mathrm{C}, 24 \mathrm{~h}\right)$ were suspended in distilled water and employed as the inoculum. The inoculum was grown in Erlenmeyer flasks containing the yeast media in a volume that respected the ratio 1:5 regarding media volume and flask volume; the flasks were incubated in rotary shaker at $150 \mathrm{rpm}, 28^{\circ} \mathrm{C}, 12 \mathrm{~h}$.

The cultivations were performed in Erlenmeyer flasks containing yeast media with and without iron supplementation in a volume that respected the ratio 1:5 regarding media volume and flask volume. The total cell concentration in the inoculum flask was determined by cell-counting (Neubauer ${ }^{\circledR}$ chamber) and a volume of inoculum suspension was transferred to the culture media in order to obtain an initial cell concentration of $10^{6}$ cells $/ \mathrm{mL}$ and the flasks were incubated in rotary shaker at $150 \mathrm{rpm}, 28^{\circ} \mathrm{C}, 20 \mathrm{~h}$.

In order to prevent the iron salt precipitation caused by steam heat sterilization, the iron salt was dissolved separately in $80 \%$ of the water content and this solution was acidified to $\mathrm{pH} 4.0$ using a $1 \mathrm{M}$ sulphuric acid solution. The nutrients were dissolved in $20 \%$ of the water content, and no $\mathrm{pH}$ adjustment was performed. The solutions were sterilized using steam heat in a vertical autoclave with a hold- ing time of $20 \min \left(120^{\circ} \mathrm{C}, 1 \mathrm{~atm}\right)$. After sterilization, the iron salt solution was poured on the nutrients solution when they were at room temperature, resulting in a final $\mathrm{pH}$ of $4.4 \pm 0.2$.

The dry cell weight was determined by drying the yeast biomass to a constant weigh at $60^{\circ} \mathrm{C}$ after centrifuging $10 \mathrm{~mL}$ of samples at $6000 \mathrm{rpm}$ and washed the cell pellet for complete medium removal.

The iron incorporated into yeast cells was determined by colorimetric methodology described elsewhere (Tamarit et al., 2006). Briefly, the yeast cells were digested using $\mathrm{HNO}_{3} 3 \%, 24 \mathrm{~h}, 98{ }^{\circ} \mathrm{C}$ to release the intracellular iron. The nitric acid containing the digested cells was mixed with sodium ascorbate, ammonium acetate and BPS, an iron chelating agent. The iron-BPS complex absorbance was recorded at $535 \mathrm{~nm}$ in a Shimadzu UV 1601 - PC spectrophotometer. This determination accompanies a calibration curve.

The experiments carried out using ferric sulphate, ferric chloride, and ferric nitrate could not be evaluated regarding biomass and intracellular iron due to iron precipitations during the sterilization process. The ferrous ion is stable in anaerobic and acidic conditions, however it rapidly oxidizes to ferric ion in aerobic environments in which $\mathrm{pH}$ is greater than 5.0. The ferric ion also readily reacts in moist environments to form precipitates (hydroxide, oxides, phosphates, and sulphates) with very low solubility, around $10^{-18} \mathrm{M}$ (Schroder et al., 2003). The iron salt precipitation in culture media could be related to the appearance of iron hydroxides, their polymerization, or formation of poorly soluble iron phosphates. Besides, ferric salts are

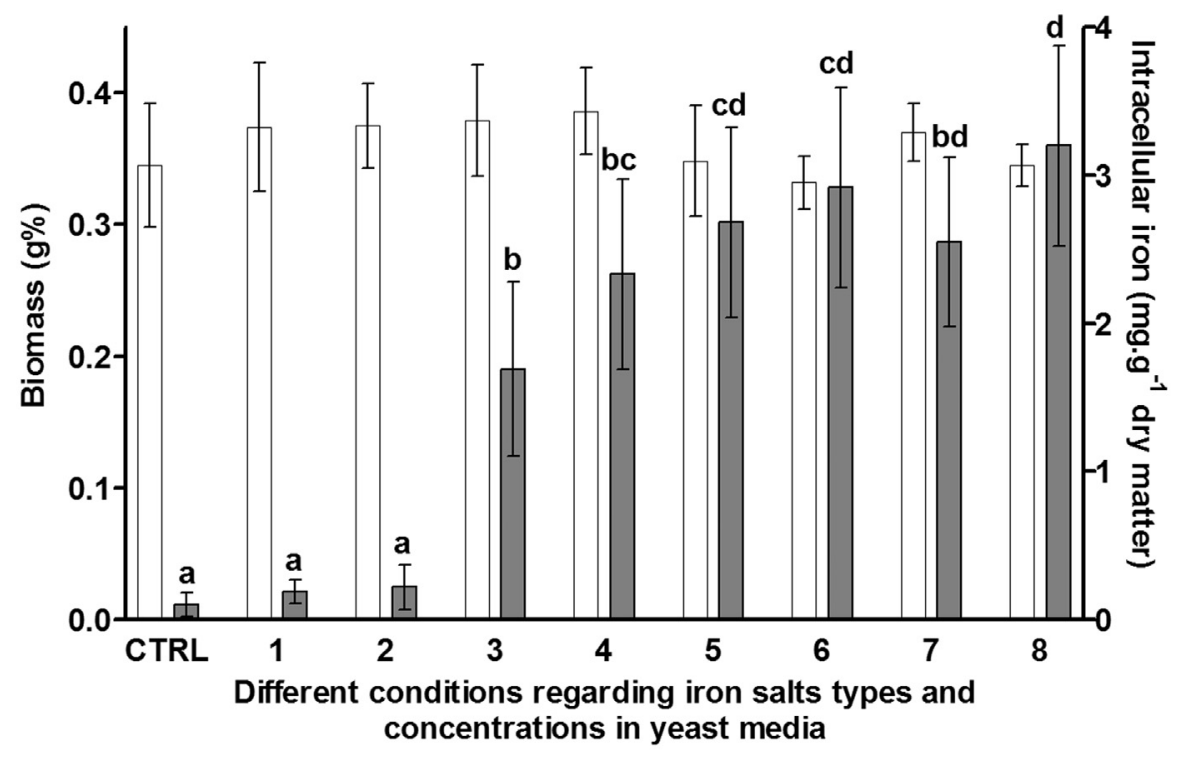

Figure 1 - The Saccharomyces cerevisiae intracellular iron concentration and biomass formation. Open and gray columns represent Saccharomyces cerevisiae biomass formation and iron uptake, respectively. The values are mean and 1-standard deviation (bars). Supplementation conditions: CTRL

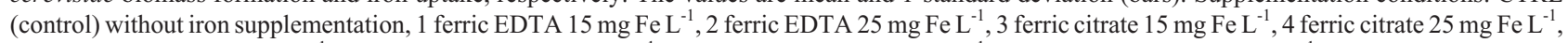
5 ferrous chloride $15 \mathrm{mg} \mathrm{Fe} \mathrm{L}^{-1}, 6$ ferrous chloride $25 \mathrm{mg} \mathrm{Fe} \mathrm{L}^{-1}, 7$ ferrous sulphate $15 \mathrm{mg} \mathrm{Fe} \mathrm{L}^{-1}, 8$ ferrous sulphate $25 \mathrm{mg} \mathrm{Fe} \mathrm{L}^{-1}$. The equal letters above gray bars represent that values of intracellular iron are not different $(t$-Student test, $\mathrm{p}<0.05)$. 
more likely to suffer oxidation reactions than ferrous salts (Pas et al., 2007).

The results were obtained from two independent duplicated experiments, and all analytical determinations were performed in triplicates. The results are presented in Figure 1 as the mean obtained \pm standard deviation (SD).

The biomass and the iron uptake values presented a normal distribution profile, according KolmogorovSmirnov test. In Figure 1, the biomass formation means in all groups (ANOVA) did not show significant difference $(p=0.239)$ when the cultures were supplemented with different iron salts. When comparing the means by $t$-Student test, a significant difference $(p=0.048)$ in biomass formation values between the cultivations supplemented with ferrous sulphate 15 and $25 \mathrm{mg} \mathrm{Fe} / \mathrm{L}$ was observed.

In Figure 1, the results show that the cultivations supplemented with ferrous chloride 15 and $25 \mathrm{mg} \mathrm{Fe} / \mathrm{L}$ and ferrous sulphate 15 and $25 \mathrm{mg} \mathrm{Fe} / \mathrm{L}$ presented higher values of intracellular iron, around $2.832 \mathrm{mg} \mathrm{Fe} / \mathrm{g}$ dry matter, 27 times the amount of iron observed in control conditions. This could be related to the fact that these iron salts are derived from strong acids, and they are probably in the dissociated form thus providing free iron to bind to the yeast cells.

The step in which iron ions are bounded to the yeast cell wall (biossorption) is a physical-chemical metabolically passive process of ion exchange with binding groups present on the surface of cell wall and is an essential step that leads to iron bioaccumulation (Chojnacka, 2010).

The difference between the cultivations could not only be related to iron, but also to the anionic part of the iron compound (Pas et al., 2007).

Nielsen and Arneborg (Nielsen et al., 2007) described that the citric acid in aerobic cultivations with a $\mathrm{pH}$ of 3.5 induces changes in the transcriptome and in the proteome in S. cerevisiae. The inhibition of yeast growth caused by citric acid is dependent on the $\mathrm{pH}$ value of the culture media. At higher $\mathrm{pH}$ values, citric acid will be in a more dissociated state, and it increases the probability to chelate ions, specially $\mathrm{Ca}^{+2}$ and $\mathrm{Mg}^{+2}$ from the culture media.

Regarding biomass formation in the cultures supplemented with ferric citrate 15 and $25 \mathrm{mg} \mathrm{Fe} / \mathrm{L}$, it could be suggested that the citrate anion present in the media did not alter the respiratory metabolism of the yeast cells, or the $\mathrm{pH}$ 4.4 do not completely dissociated the ferric citrate, explaining also the lower amount of intracellular iron when compared to the cultivations supplemented with ferrous sulphate and ferrous chloride.

The intracellular iron content in the yeast cells grown in cultivations supplemented with ferric EDTA was around $0.207 \mathrm{mg} \mathrm{Fe} / \mathrm{g}$ dry matter. These values are equivalent to intracellular iron content in the yeast cells grown in cultivations without iron supplementation (control), $0.103 \mathrm{mg}$ $\mathrm{Fe} / \mathrm{g}$ dry matter. This result is in accordance to Pas et al. (Pas et al., 2007). The low intake of iron when ferric EDTA is added to the culture broth probably occurs because this salt forms a stable complex in the culture media, as a result, there is less free iron to bind to the yeast cells. Another explanation could be associated to the metaloreductase activity at the cell surfaces that reduces ferric ions to ferrous ions. The free EDTA binds to the ferrous ion generated by the mettaloreductase, and in this form, the Fe(II)-EDTA complex is inaccessible to yeast cells (PAS et al., 2007). The ferric EDTA was not favourable to promote iron uptake by $S$. cerevisiae in the concentrations employed.

In humans, iron is weakly absorbed, especially if the diet is poor in ascorbic acid and based on vegetables. The iron deficiency is the most common nutritional deficiency in the world - considered a public health problem - especially among children and women of childbearing age (Philpott et al., 2008). The iron deficiency indicates iron depletion and iron-deficiency anaemia in the worst case (Chang et al., 2005).

According to the World Health Organization, the recommended iron intake considering an iron bioavailability of $10 \%$ varies from $5.8 \mathrm{mg}$ /day (infants up to 1 year) to $32.7 \mathrm{mg} /$ day (females with 11 to 14 years). Considering the results obtained for yeasts cultivated in media supplemented with ferric citrate, ferrous chloride or ferrous sulphate, $9 \mathrm{~g}$ of the dried yeast biomass would be sufficient to provide the maximum iron requirement intake per day (Who, 2004). As the daily recommended intake of dried yeasts cells is no more than $30 \mathrm{~g}$ (Sgarbieri et al., 1999), the yeast biomass enriched with iron could represent a more secure and practical solution to anaemia prevention (StehlikThomas et al., 2003; Gligic, et al., 2004). Besides, when iron is bounded to organic carriers, as macromolecules found in yeast cells, it has better absorbability and is less toxic to organisms (Gaudreau et al., 2001; Pas et al., 2007). The studies evaluating cellular distribution of microelements in Saccharomyces cerevisiae enriched with chrome, iron, selenium, and zinc determined that $68 \%$ to $88 \%$ of these microelements are probably linked to organic molecules, such as proteins and carbohydrates (Varga et al., 2002).

It has been shown that iron enriched baker's yeast Saccharomyces cerevisiae maintains its fermentative properties and bakery characteristics. A bread produced using iron-enriched yeast presented six times more iron than a bread produced using the yeast obtained by cultivation without iron supplementation (Gaensly et al., 2011).

In summary, different iron salts added to the growth media in concentrations from 15 to $25 \mathrm{mg} \mathrm{Fe} / \mathrm{L}$ can influence iron uptake by the yeast Saccharomyces cerevisiae but did not interfere the biomass formation. The ferrous sulfate at 15 to $25 \mathrm{mg} \mathrm{Fe} / \mathrm{L}$ is recommended as an iron supplement due to its efficacy, low cost, stability in the culture media, and compatibility of the anionic part of this salt with Saccharomyces cerevisiae metabolism. 


\section{Acknowledgments}

The authors acknowledge the financial support provided by CAPES Brazilian research supporting foundation (Coordenação de Aperfeiçoamento de Pessoal de Nível Superior) and to the Applied Microbiology Specialization Course, at Federal University of Parana (Universidade Federal do Paraná).

\section{References}

Askwith CC, De Silva D, Kaplan J (1996) Molecular biology of iron acquisition in Saccharomyces cerevisiae. Mol Microbiol 20:27-34.

Chang YJ, Jo MY, Hwang EH, Park CU, Kim KS (2005) Recovery from iron deficiency in rats by the intake of recombinant yeast producing human $\mathrm{H}$-ferritin. Nutrition 21:520-524.

Chojnacka K (2010) Biosorption and bioaccumulation - The prospects for practical applications. Environ. Int. 36:299-307.

De Nicola R, Walker GM (2009) Accumulation and cellular distribution of zinc by brewing yeast. Enzyme Microb Technol 44:210-216.

De Siloniz MI, Balsalobre L, Alba C, Valderrama MJ, Peinado JM (2002) Feasibility of copper uptake by the yeast Pichia guilliermondii isolated from sewage sludge. Res Microbiol 153:173-180.

Donmez G, Aksu Z (1999) The effect of copper(II) ions on the growth and bioaccumulation properties of some yeasts. Process Biochem 35:135-142.

Dostalek P, Patzak M, Matejka P (2004) Influence os specific growth limitation on biosorption of heavy metals by Saccharomyces cerevisiae. Int Biodeter Biodegrad 54:203207.

Gaensly F, Wille GMFDC, Brand D, Bonfim TMB (2011) Iron enriched Saccharomyces cerevisiae maintains its fermenting power and bakery properties. Ciên Tecnol Aliment 31:980-983.

Gaudreau H, Tompkins TA, Champagne CP (2001) The distribution of iron in iron-enriched cells of Saccharomyces cerevisiae. Acta Aliment 30:355-361.

Gharieb MM, Gadd GM (2004) The kinetics of 75[Se]-selenite uptake by Saccharomyces cerevisiae and the vacuolization response to high concentrations. Mycol Res 108:1415-1422.
Gligic L, Palic T, Nikolovski J (2004) The beneficial effects of iron-enriched yeast Saccharomyces cerevisiae biomass in poultry breeding. Folia Veterinaria 48:104-107.

Gligic L, Vujovic N, Stevovic B, Manic J (2003) Optimal conditions for accumulation of bioavailable iron in Saccharomyces cerevisiae cells. Boll Chim Farm 142:330-332.

Mrvcic J, Stanzer D, Stehlik-Tomas V, Skevin D, Grba S (2007) Optimization of bioprocess for production of copperenriched biomass of industrially important microorganism Saccharomyces cerevisiae. J Biosci Bioeng 103:331-337.

Nielsen MK, Arneborg N (2007) The effect of citric acid and pH on growth and metabolism of anaerobic Saccharomyces cerevisiae and Zygosaccharomyces bailii cultures. Food Microbiol 24:101-105.

Pas M, Piskur B, Sustaric M, Raspor P (2007) Iron enriched yeast biomass - a promising mineral feed supplement. Bioresour Technol 98:1622-1628.

Philpott CC, Protchenko O (2008) Response to iron deprivation in Saccharomyces cerevisiae. Eukaryot. Cell 7:20-27.

Raguzzi F, Lesuisse E, Crichton RR (1988) Iron storage in Saccharomyces cerevisiae. FEBS Letters 231:253-258.

Schroder I, Johnson E, De Vries S (2003) Microbial ferric iron reductases. FEMS Microbiol Rev 27:427-447.

Sgarbieri VC, Alvim ID, Vilela ESD, Baldini VLS, Bragagnolo N (1999) Produção piloto de derivados de levedura (Saccharomyces sp.) para uso como ingrediente na formulação de alimentos. Braz J of Food Technol 2:119-125.

Shoeib T, Mester Z (2007) Towards the characterization of metal binding proteins in metal enriched yeast. Microchem $\mathrm{J}$ 85:329-340.

Stehlik-Thomas V, Grba S, Stanzer D, Vahcic N, Zetic VG (2003) Uptake of iron by yeast cells and its impact on biomass production. Acta Aliment 32:279-287.

Tamarit J, Irazusta V, Moreno-Cermeno A, Ros J (2006) Colorimetric assay for the quantitation of iron in yeast. Anal Biochem 351:149-151.

Varga E, Maráz A (2002) Yeast cells as sources of essential microelements and vitamins B1 and B2. Acta Aliment 31:393-405.

World Health Organization (WHO). (2004) Vitamin and mineral requirements in human nutrition. Available at: http://whqlibdoc.who.int/publications/2004/9241546123.pdf. Accessed 22 abr 2008.

All the content of the journal, except where otherwise noted, is licensed under a Creative Commons License CC BY-NC. 